\title{
Peculiaridades sobre a dimensão urbana de pequenas cidades no contexto amazônico
}

\author{
Peculiarities on the urban dimension in small towns in the Amazon region \\ Giselle de Lourdes Bangoim Sakatauskas * \\ Joana Valente Santana **
}

\begin{abstract}
Resumo:
O presente artigo apresenta um estudo que buscou discutir a dimensão urbana de pequenas cidades no contexto amazônico, evidenciando o conceito de pequenas cidades. A argumentação considera que a dinâmica econômica, social e cultural das pequenas cidades amazônicas é pouco conhecida pelo governo federal, assim, estas são, fragilmente, incorporadas no planejamento urbano brasileiro, bem como, recebem pouco investimento no que se refere às políticas públicas e sociais. A abordagem teórico-metodológica da investigação está fundamentada no método dialético da teoria social de Marx, tendo como procedimento metodológico o levantamento bibliográfico. A partir dos estudos sobre as pequenas cidades na Amazônia foi possível destacar, como elementos constitutivos peculiares à dimensão urbana dessas cidades: a) baixa densidade populacional; b) precário acesso à infraestrutura física e social; c) existência de modos de vida diferenciados culturalmente (índios, quilombolas, ribeirinhos), com uma complexa rede urbana/rural; d) difícil acesso devido à distância geográfica, com algumas cidades acessadas por rio; e) agravamento das expressões da questão social (renda, trabalho, acesso às políticas sociais); e) baixa capacidade administrativa municipal e; f) resistência dos povos indígenas e comunidades tradicionais pelo modo de viver diferenciado (quilombolas, ribeirinhos), o que ratifica a necessidade de incorporação dessas peculiaridades no planejamento e execução de políticas públicas governamentais.
\end{abstract}

Palavras-chave: Pequenas Cidades. Amazônia. Peculiaridades. Dimensão urbana. Planejamento governamental.

\begin{abstract}
:
This article discusses the urban dimension in small towns in the Amazon region, highlighting the concept of small towns. The argument considers that economic, social and cultural dynamics of small Amazonian cities is little known by the federal government, and these loosely incorporated cities in the Brazilian urban planning as well as receive little investment with regard to public and social policies. The theoretical and methodological approach to research is based on the dialectical method of social theory of Marx, and the methodological procedure the literature. From the studies of small towns in the Amazon can stand out as unique building blocks to the urban dimension of these cities: the low population density; b) poor access to physical and social infrastructure; c) the existence of culturally different
\end{abstract}

\footnotetext{
* Assistente Social formada pela Universidade Federal do Pará. Mestre em Serviço Social pela Universidade Federal do Pará. E-mail: gibangoim.gisa@gmail.com

** Docente da Faculdade de Serviço Social da UFPA. Doutora em Serviço Social pela Universidade Federal do Rio de Janeiro. E-mail: joanavalente@ufpa.br
} 
ways of life (Indians, quilombolas, riparian) with a complex urban / rural network; d) difficult to access by geographic distance, with some cities accessed by the river; e) worsening of the terms of the social question (income, employment, access to social policies); e) low municipal and administrative capacity; f) indigenous peoples' resistance and traditional communities at different live mode (maroon and riverine), which confirms the need for incorporation of these peculiarities in the planning and execution of government policies.

Key words: Small towns. Amazon. Peculiarities. Urban dimension. Government planning.

\section{Introdução}

O presente estudo teve por objetivo discutir a dimensão urbana em pequenas cidades no contexto amazônico, evidenciando o conceito de pequenas cidades ${ }^{1}$. Essa discussão justifica-se por que as pequenas cidades amazônicas têm sido invisíveis ao planejamento urbano brasileiro, seja pela falta de conhecimento por parte do governo federal em relação às suas peculiaridades ou por sua pouca atratividade para as empresas capitalistas, no contexto da divisão social e territorial do trabalho, o que desencadeia, como consequência, frágil investimento do Estado no que se refere às políticas de infraestrutura física e social.

Ademais, a Política Nacional de Desenvolvimento Urbano não abarca, suficientemente, a diversidade urbana e regional, motivo pelo qual as ações governamentais, muitas vezes, não são adequadas para o enfrentamento dos problemas urbanos nos municípios amazônicos. Após décadas de esforços e lutas voltados para a democratização do país e a descentralização administrativa, expressas na Constituição Federal de 1988, tem início uma discussão sobre a diversidade de realidades municipais brasileiras, no âmbito qual, argumentos e trabalhos analíticos defendem a necessidade de se elaborar políticas públicas de abrangência nacional que levem em consideração as particularidades regionais, pois os municípios sempre foram tratados de modo homogêneo pelo Governo Federal.

\footnotetext{
1 O presente artigo é parte da dissertação de Mestrado intitulada "Precariedade habitacional em pequenas cidades paraenses: análise a partir dos Planos Locais de Habitação de Interesse Social”, defendida no âmbito do Programa de Pós-Graduação em Serviço Social, em nível de Mestrado. A referida dissertação analisa a precariedade habitacional em pequenas cidades paraenses, tomando por base a análise dos assentamentos precários de oito cidades paraenses (Aveiro, Anapu, Senador José Porfírio, Curionópolis, Eldorado dos Carajás, São João do Araguaia, Faro e Placas) articulada à dimensão de renda e à lógica do Estado capitalista.
} 
A abordagem teórico-metodológica do estudo está fundamentada no método dialético da teoria social de Marx, com o objetivo de apreender as múltiplas determinações do fenômeno estudado (MARX, 1974). Os procedimentos metodológicos ancoram-se na pesquisa qualitativa (LAKATOS; MARCONI, 2011) com base em levantamento bibliográfico.

Os resultados da pesquisa são apresentados em dois tópicos, sendo o primeiro uma discussão conceitual sobre pequenas cidades, e o segundo, uma explanação sobre as peculiaridades da dimensão urbana no contexto amazônico, seguidos das considerações finais.

\section{Discussão conceitual sobre pequenas cidades}

Antes de adentrar na temática das pequenas cidades, é necessário conhecer o conceito de cidade. Quando se pensa em cidade em uma perspectiva conceitual descritiva, esta se apresenta como um espaço que é marcado por elementos que a constituem, como lugar cujo meio de existência consiste na concentração de trabalho baseado no comércio e na indústria (CASTELLS, 1983) ${ }^{2}$.

Castells (1983) afirma que a cidade é uma estrutura social e espacial complexa, expressão do processo de apropriação e de reinvestimento do produto do trabalho. Em relação à divisão do trabalho entre a cidade e o campo, assevera que esses dois espaços não podem ser entendidos separadamente. Segundo Castells (1983, p. 42), ao contrário, a cidade e o campo "estão intimamente ligados no âmago do mesmo processo de produção das formas sociais, mesmo que, do ponto de vista destas próprias formas, estejamos na presença de duas situações diferentes. "

A cidade não tem uma produção espontânea, mas uma série de situações e agentes sociais que a produzem. Segundo Corrêa (2004), dentro do processo de produção social, encontram-se os agentes sociais: Estado; proprietários fundiários; promotores imobiliários; grandes industriais; e grupos sociais excluídos, que fazem e refazem a cidade, pois tais agentes possuem uma complexa ação que deriva da dinâmica interna do capital.

\footnotetext{
2 Manuel Castells foi uma referência na literatura marxista nos estudos sobre a questão urbana. Embora, na atualidade o referido autor tenha abandonado a tradição marxiana, a conceituação sobre cidades com base nessa literatura permanece válida.
} 
Para Lefebvre (1969), as cidades expressam o processo de acumulação e de concentração de capital e a precarização crescente das relações de trabalho que aprofundam e atualizam as contradições entre capital e trabalho. A cidade é o espaço mais visível e concentrado das diferenças de classe e das contradições sociais.

No que se refere ao estudo de pequenas cidades na Amazônia, destacam-se as produções de autores ${ }^{3}$ que voltam suas análises para: a dimensão urbano/rural; o padrão de ocupação urbana; o planejamento urbano; elementos da pluralidade e singularidade das cidades; a discussão conceitual; a questão da habitação; a rede urbana e cidades ribeirinhas.

Conceitualmente, os estudos sobre as pequenas cidades apontam a inserção destas no âmbito da divisão social e territorial do trabalho, inerente à lógica da produção e reprodução das relações sociais capitalistas, o que significa que as mesmas desenvolvem um papel específico nessa lógica (SANTANA, 2012). Essa discussão teórica é fundamental para a apreensão da produção do espaço das pequenas cidades no Brasil e, particularmente, na Amazônia.

\begin{abstract}
Assim, no recente processo produtivo, as cidades podem adequar-se, ou não, às exigências das empresas nacionais ou globais, isto é, nem todas as cidades são imediatamente incorporadas à dinâmica relativa ao sistema de cidades sob a lógica capitalista. Desta forma, as pequenas cidades [...], somente serão absorvidas quando de alguma forma contribuírem para a ampliação do lucro das empresas capitalistas (SANTANA, 2012, p. 86).
\end{abstract}

Nos estudos sobre as pequenas cidades do Brasil, há uma tendência em classificálas tendo como referência o quantitativo populacional. Assim, alguns estudiosos consideram como pequena cidade aquelas cuja população não ultrapassa vinte mil habitantes, enquanto outros consideram as que têm apenas dez mil habitantes ${ }^{4}$. Este parâmetro é utilizado também por órgãos oficiais, como o Instituto Brasileiro de Geografia e Estatística (IBGE) e o Instituto Brasileiro de Administração Municipal (IBAM),

3 Cardoso (2006), Castro (2008), Oliveira (1999), Santana, Holanda e Moura (2012), Trindade Junior et al. (2009), Trindade Junior e Tavares (2008), dentre outros.

${ }^{4}$ Geralmente os estudos funcionais ou que priorizam o sistema hierárquico das cidades usam terminologias similares às de cidades pequenas, médias e grandes. Para tanto, tomam como base os dados referentes a seus contingentes populacionais. Assim, na classe de cidades pequenas inserem-se aquelas que possuem até 20 mil habitantes; acima deste montante são classificadas como cidades médias e aquelas com mais de 500 mil habitantes são consideradas cidades grandes. Este critério, com algumas variantes, tem sido adotado pelas instituições de estudos estatísticos (MAIA, 2010). 
dentre outros. Conforme afirmado anteriormente, em sua maioria, o tamanho da cidade é medido pelo número de habitantes, e a partir desse quesito, são classificadas como pequenas, médias e grandes. As cidades classificadas como pequenas possuem até 20.000 habitantes, acima deste montante, até 500.000 habitantes, estão as cidades denominadas de médias, e as que possuem mais de 500.000 habitantes são as consideradas grandes cidades. Esta é a classificação do IBGE e da maioria dos estudos que versam sobre esse assunto.

Embora o aspecto quantitativo populacional seja bastante significativo, não significa que seja a única forma consistente para se definir e compreendera pequena cidade. Desta maneira, compactua-se com a ideia de que tal definição seja simplista diante de tamanha complexidade, isto é, esta perspectiva de compreensão apresenta-se como frágil e insuficiente para prover, teoricamente, a temática das pequenas cidades.

Quem nunca ouviu indagações a respeito das cidades pequenas, tais como: cidade pequena pacata, cidade pequena miserável, cidade pequena que vivi, nasci ou que conheci? Contudo, esse movimento não cessa e possui uso muito amplo, reproduzindo-se como recortes espaciais e como uma percepção do espaço, baseada na vivência e no sentido prático da construção social e econômica empregada pelas pessoas corriqueiramente (JURADO, 2011, p. 36).

De acordo com Sposito (2009), é fundamental que se empreenda um esforço para que se possa superar a adoção desses dois adjetivos, pequenas e médias, para classificar as cidades, pois estes não são suficientes para caracterizar as cidades não metropolitanas. A realidade das cidades pequenas e médias é, extremamente, plural para que se continue adotando, no plano teórico-conceitual, esses dois adjetivos. Portanto, é preciso repensar essas expressões para que se chegue a denominações que traduzam o conteúdo das realidades analisadas.

A partir dos dados populacionais, as pequenas cidades estariam em posição inferior dentro da hierarquia urbana. No entanto, os estudos sobre a rede urbana já têm apontado para outros itens fundamentais para a análise da rede e da hierarquia urbanas. Tem destaque o autor Roberto Lobato Corrêa (2003) que elegeu algumas linhas de diferenciação para o estudo da rede urbana: origem, tamanho e funções. A origem "inclui o contexto econômico e político e os agentes sociais das criações urbanas", o tamanho 
varia de acordo com o número de habitantes, e as funções são analisadas "segundo agregados econômicos distintos", como "o valor da produção industrial e da receita do comércio e serviços e a renda de seus habitantes" (CORRÊA, 2003, p. 134-135).

Santos (1982), ao abordar o tema, afirma que essas cidades são mais comumente denominadas, na literatura especializada, como cidades pequenas, no entanto, ele opta pela nomenclatura cidades locais, por vários motivos. O autor discute a possibilidade de se falar em "verdadeiras cidades" e "pseudocidades".

Quando se fala em cidades pequenas, a noção de volume da população vem logo à mente. Aceitar um número mínimo, como o fizeram diversos países e também as Nações Unidas, para caracterizar diferentes tipos de cidades no mundo inteiro, é incorrer no perigo de uma generalização perigosa. 0 fenômeno urbano, abordado de um ponto de vista funcional, é antes um fenômeno qualitativo e apresenta certos aspectos morfológicos próprios a cada civilização e admite expressão quantitativa, sendo isto outro problema (SANTOS, 1982, p. 69-70).

As cidades locais, de acordo com as proposições do autor, são as que dispõem de uma atividade polarizante e, conforme as funções que exercem, em primeiro nível, denominam-se cidades de subsistência.

Segundo o autor, essa expressão, ou seja, cidade de subsistência, deve ser utilizada para designar os aglomerados populacionais com uma dimensão mínima e que apresentam "um crescimento autossustentado e um domínio territorial" que respondem às "necessidades vitais mínimas, reais ou criadas de toda uma população, função esta que implica em uma vida de relações" (SANTOS, 1982, p. 71).

\footnotetext{
Poderíamos definir a cidade local como a aglomeração capaz de responder às necessidades vitais mínimas, reais ou criadas, de toda uma população, função esta que implica uma vida de relações. A atividade de troca, pura e simples, não dá lugar à criação de uma cidade. Para que exista uma cidade deve haver necessidades que exijam ser satisfeitas regularmente - necessidades quase sempre impostas de fora da comunidade - mas é necessário, por outro lado, que exista criação de atividades regulares especialmente destinadas a responder a essas necessidades (SANTOS, 1982, p. 71).
}

As cidades têm suas singularidades, o que não significa que elas são isoladas, visto que existe, entre elas, segundo o autor, uma inter-relação que se materializa através dos centros de consumo, de comercialização, de serviços, de transporte e de distribuição, que 
podem ainda se posicionar como centros de pequena escala de manufaturas, de difusão de inovações e interação social (SANTOS, 1994).

As pequenas cidades, no Brasil, devem ser compreendidas enquanto espacialidades que compõem a totalidade do espaço brasileiro, marcadas pela diversidade. Tal característica pode ser entendida a partir do contexto regional no qual estão inseridas, de como surgiram e das transformações espaciais sofreram.

Alguns estudos versam sobre a temática das pequenas cidades, assim, há trabalhos mais empíricos e até os que fizeram um resgate histórico da origem dos aglomerados. No entanto, não têm tanta repercussão, não por sua importância, mas pela pouca interlocução com a sociedade, pois os grandes fóruns que têm discutido essa temática pouco têm debatido sobre o tema das pequenas cidades. Geralmente, as discussões são acerca das metrópoles, uma vez que os grandes problemas urbanos, normalmente, surgem e ocorrem nas grandes cidades. Registra-se, ainda, a incipiente produção, na literatura acadêmica, sobre as pequenas cidades. Segundo Lopes:

\footnotetext{
Parte dessa situação decorre do fato de elas serem praticamente invisíveis aos olhos dos técnicos e demais possíveis interessados, a exemplo de planejadores governamentais. Em trabalhos científicos, mesmo buscando características que possam ser generalizadas, focalizam-se, especialmente, as grandes unidades, pois além de saltar aos olhos, individualmente, seus problemas são também de grande magnitude. Daí que as pequenas cidades dispersas no espaço são tidas como sem importância e não se tornam objeto preferencial de pesquisa (LOPES, 2010, p. 77).
}

A palavra "pequena" faz referência ao tamanho da cidade, que tem relação com o estudo das redes e hierarquias urbanas, produzido, principalmente, pelo Instituto Brasileiro de Geografia e Estatística.

O conceito de pequena cidade é daqueles de difícil elaboração. As localidades assim denominadas oferecem elementos para se discutir não só o conceito de cidade, pois nelas são avaliados os qualificativos que devem compor o limiar entre a cidade e a não-cidade. As pequenas cidades são localidades em que tais requisitos se apresentam, ainda que com patamares mínimos (ENDLICH, 2006, p. 85).

Ressalta-se que o parâmetro nacional para a classificação e definição das pequenas cidades tem sido, geralmente, o número de habitantes, que as categoriza como pequenas, médias e grandes, entretanto, este pode ser insuficiente, principalmente, 
quando se que sabe essas cidades são marcadas pela diversidade e que suas características devem ser entendidas a partir do contexto regional onde estão inseridas.

Portanto, deve-se buscar compreender a pequena cidade a partir das relações que são estabelecidas em seu contexto urbano regional, assim, o que definirá a pequena cidade é sua participação na divisão territorial do trabalho, uma vez que o entendimento dessa participação sugere a análise do processo de produção do espaço em sua totalidade, o que implica sua inserção da produção e reprodução do capital.

\section{Peculiaridades sobre a Dimensão Urbana de Pequenas Cidades no Contexto}

\section{Amazônico}

As pequenas cidades da Amazônia ${ }^{5}$, que se encontram distantes das grandes, têm formas de uso e ocupação do solo, tanto urbano como rural, que expressam os hábitos de moradia peculiares à região, geralmente, construções erigidas em locais próximos aos rios e florestas. No entanto, revelam os mesmos padrões desiguais que caracterizam o processo de urbanização brasileira, pautados na lógica da produção de cidades no âmbito do modo capitalista de produção, no qual a maioria da população de baixa renda se vê obrigada a buscar alternativas de acesso à terra.

Normalmente, essa população habita as áreas precárias do ponto de vista de infraestrutura urbana básica. Conforme Nakano (2012), a população de baixa renda procura alternativas viabilizadas em contextos periurbanos ${ }^{6}$, que resultam em ocupações com alta densidade e, no caso dos municípios externos aos focos do dinamismo econômico, produzem assentamentos dispersos, construídos com base na cultura e nos saberes populares.

Para esta análise, é relevante entender tanto os resultados históricos da presença do capital na região Amazônica, como o contexto político em que ocorre a ocupação

\footnotetext{
${ }^{5}$ A discussão sobre pequenas cidades no contexto amazônico deve ser articulada à ocupação da Amazônia no contexto da acumulação do capital e ao papel dessa região no processo da divisão social e territorial do trabalho. Considerando os limites do artigo, registra-se que a fundamentação teórica sobre esse assunto está amparada em Becker (2013), Carvalho (2012), Leal (2010), Nascimento e Sá (2012), Picoli (2006), Rodrigues (1996), entre outros autores.

6 "[...] áreas periurbanas que se constituem cada vez mais em zonas de transição demarcadas pelo avanço crescente do urbano sobre o campo, sobre territórios organizados por modos de vida culturalmente diversos, como os territórios quilombolas e indígenas, as áreas ocupadas por população ribeirinha, como nas regiões Centro-Oeste e Norte do Brasil, redefinindo a relação cidade-campo que não desaparece, mas subordina-se à relação urbano-rural" (CARDOSO, 2012, p. 33).
} 
dessa região. Na Amazônia, a urbanização desenvolveu-se de forma desigual e combinada (RIBEIRO, 2012) e tem relação com a intervenção estatal, principalmente, a partir da década de 1960, por meio do controle da terra, da política de migração induzida e do incentivo aos grandes empreendimentos privados com vistas ao desenvolvimento da região.

Uma parte significativa da população urbana encontra-se em pequenas cidades ${ }^{7}$, localizadas na beira dos rios ou das estradas, e estas são espaços produzidos socialmente e refletem as condições específicas do lugar e dos conflitos que têm várias dimensões, econômicas, políticas e ideológicas, e retratam o vivido de quem as constrói.

\begin{abstract}
Muitas pequenas cidades amazônicas são indígenas na composição demográfica, na cultura e na língua. Tem questões urbanas que emanam desse universo cultural. São igualmente inúmeros os povoados quilombolas, ou comunidades, com temas urbanos e demandas de direitos aos bens e serviços considerados urbanos. Essa realidade brasileira, multiétnica e multilinguística, é ainda pouco reconhecida na sociedade, mas também no campo da pesquisa e na ação política. Daí a necessidade de se compreender o que são essas cidades, mas com uma perspectiva teórica que abra as possibilidades de entendimento desse universo incomum a teorias convencionais sobre o urbano e a urbanização, para se poder captar a natureza de suas redes e as territorialidades em jogo na sua relação com o território da floresta tropical (CASTRO, 2008, p. 16).
\end{abstract}

Em sua grande maioria, as pequenas cidades da Amazônia possuem pouca ou nenhuma importância para o restante do país, no entanto, têm organização e estrutura que extrapolam sua dimensão específica. Elas possuem instituições regionais, nacionais e internacionais que influenciam, diretamente, seu cotidiano. Essas relações portam significado cultural e refletem a configuração de um urbano em construção na Amazônia, cujas espacialidades são constituídas de fatores externos e internos, assim, "cada uma dessas cidades é um lugar específico, o que não quer dizer exclusivo, pois faz parte de um contexto maior" (OLIVEIRA, 1999, p. 206).

É um desafio decifrar o urbano na Amazônia, partindo-se do princípio de que a densidade populacional, na região, é menor do que a de outras regiões do país, e também

\footnotetext{
7 "Essas pequenas cidades têm um padrão urbano característicos com ruas e caminhos que terminam invariavelmente no porto. A rua da frente ou a rua primeira tem as melhores casas e as ruas de trás, casebres cobertos de palha. As pequenas cidades da Amazônia parecem ter sido criadas para serem vistas de longe, pois de perto toda a dimensão de beleza que existia no primeiro olhar esvai-se no arruamento caótico, nas casas novas, mas com as fachadas desbotadas e precocemente envelhecidas. Talvez fosse melhor que delas só tivéssemos a primeira impressão" (OLIVEIRA, 1999, p. 200-201).
} 
por que o processo de ocupação e urbanização da região foi diferenciado, por isso, essa singularidade não pode ser desconsiderada. Por esse motivo, é necessário entender: as racionalidades em jogo; as relações interculturais em uma região onde o pluriétnico se expressa no urbano; as relações monetarizadas, amplamente articuladas ao mercado globalizado; e o mercado de trabalho mesclado com a rede informal (CASTRO, 2003).

As cidades da Amazônia sofreram influência de um contexto cultural mais amplo, e, atualmente, a tendência tem sido de enfraquecimento da cultural local, que é resultante da experiência dos que chegam com os que estão no local.

\footnotetext{
O rio não é mais o meio de circulação para a população local, nem a principal fonte de sua subsistência, mas a matéria-prima para a produção de energia elétrica. A população que ocupava suas margens foi reduzida à abstração de dados estatísticos ou de categorias não menos abstratas de "atingidos pela barragem", "população à jusante", etc., a enriquecer relatórios manipulados nos gabinetes oficiais. O espaço perdeu uma das dimensões da vida, simbolizado pelo rio (OLIVEIRA, 1999, p. 210).
}

Ao mesmo tempo em que as cidades da Amazônia apresentam características semelhantes às do restante do país, no que concerne à apropriação do solo, observa-se que as condições de urbanização foram bastante diferenciadas em relação às outras cidades brasileiras, devido ao isolamento dos núcleos urbanos e à intervenção estatal no processo de ocupação da região, com o objetivo de solucionar os conflitos no campo, decorrentes da falta de regularização fundiária.

\footnotetext{
Tais clivagens revelam as desigualdades sociais e econômicas que atravessam toda sociedade brasileira e ganham contornos específicos em contexto amazônico por causa da justaposição com práticas culturais tradicionais que convivem tanto com atividades econômicas modernas quanto com novos padrões de consumo das mercadorias industrializadas (NAKANO, 2011, p. 48).
}

A região Norte, por exemplo, apresenta características específicas, a saber: o processo histórico de sua ocupação; os baixos índices socioeconômicos; as características climáticas e físicas da região; a questão cultural, fortemente, presente; e os conflitos fundiários e ambientais. As políticas setoriais elaboradas pelo Governo Federal, entretanto, têm sido pensadas a partir de realidades das regiões Sul e Sudeste, assim, para a Amazônia, o maior desafio é a inclusão, no planejamento e na execução, de 
políticas públicas voltadas para as particularidades inerentes à região (SANTANA; HOLANDA, 2012).

Corrêa (1989) afirma que, através da periodização da rede urbana amazônica, é possível identificar o percurso histórico vivenciado pela formação urbana e regional, bem como, seu significado e natureza. A periodização, nesse contexto, é interpretada como função da variedade e das intensidades dos processos aos quais uma determinada região foi submetida. Uma rede urbana, de acordo com o autor, é composta por três componentes: uma economia de mercado, existência de pontos fixos no território, e, por fim, existência de um mínimo de articulação entre esses núcleos ${ }^{8}$.

O período referente à fundação de Belém até a década de 1960 corresponde à rede dendrítica. Essa forma mais simples de rede urbana tem origem no período colonial e pressupõe a ideia de cidade localizada, estrategicamente, para a conquista e a defesa de um determinado território. Esse período apresenta um considerável contingente de pequenos núcleos e ausência de centros intermediários. A transição da rede dendrítica para a complexa pressupõe um maior nível de complexidade na esfera da produção, circulação e consumo, além do aparecimento de uma divisão intra-regional do trabalho, capaz de romper o caráter dos fluxos de produção em uma única direção (CORRÊA, 1989).

Para o autor, a rede urbana ${ }^{9}$ é produto, meio e condição das relações sociais, é dotada de vida social e é onde se dá a produção e apropriação do excedente capitalista. É através da articulação entre as diversas funções de cidade (comércio atacadista e varejista, bancos, indústrias, serviços de transporte, armazéns, educação, saúde etc.) que se torna viável a produção, a circulação, o consumo e, consequentemente, a divisão territorial do trabalho. Conforme Corrêa:

[...] a rede urbana é a forma espacial através da qual, no capitalismo, se dá a criação, a apropriação e a circulação do valor excedente [...]. Neste sentido, uma classificação funcional de cidades, Isto é, a descrição da divisão territorial do trabalho em termos urbanos deve procurar dar conta dos papéis que cada

\footnotetext{
8"Para realizar a tipificação da rede urbana na Amazônia, que viabilize reconhecer tanto as semelhanças como as diferenças e o perfil de urbanização, torna-se necessário (re)discutir a periodização da rede urbana da região amazônica, em especial a da calha Solimões-Amazonas na qual se situam as principais cidades do estado do Amazonas" (SCHOR et al., 2009, p. 36).

9 "No caso da Amazônia, a rede urbana deve ser analisada e compreendida considerando-se a inserção, a cada momento, da região em um contexto externo a ela, seja internacional, nacional ou abrangendo ambos." (PEREIRA, 2006, p. 27-28).
} 
cidade cumpre na criação, na apropriação e circulação do valor excedente (CORRÊA, 1989, p. 52).

As cidades constituem-se como lugares de reprodução das relações sociais e, portanto, são o lócus onde o Estado realiza intervenções na produção do espaço, de modo a possibilitar a expansão de novas formas de relação da produção na região, o que representa uma medida essencial para o desenvolvimento do capital.

Na Amazônia, há inúmeros conflitos que resultam da imbricação dos processos desenvolvidos por múltiplos agentes portadores de diferentes práticas sócio-espaciais, o que faz da região um lugar por excelência de lutas sociais. Nesse sentido, segundo Oliveira:

\begin{abstract}
Observe-se que nas cidades da Amazônia podem emergir formas de relações sociais que não se tornaram vencedoras, que revelam o virtual ainda não transformado em real, mas que se colocam num determinado momento histórico como possibilidade de emersão de outros modos de vida, de espacialidades diferentes às que se tornaram dominantes. A resistência, em diferentes épocas, constitui-se do ponto de vista sócio-espacial, no inconformismo como as novas relações sociais de produção que se impunham. Este processo, contínuo, mas não linear no tempo e no espaço, reflete múltiplas dimensões da vida, cujos resíduos ficaram na paisagem (OLIVEIRA, 1999, p. 199).
\end{abstract}

Como sinaliza Vicentini (1994), cidades tradicionais, cidades da colonização, cidades espontâneas, vinculadas ao garimpo ou a projeto extrativistas, são facetas complexas do processo de transformação pelo qual passou o urbano na região. As características das cidades da Amazônia têm relação direta com as políticas de desenvolvimento regional, que resultaram na concentração de grandes contingentes populacionais em algumas cidades carentes de bens, trabalho e serviços públicos adequados.

A política de desenvolvimento regional pensada para a Amazônia produziu um conjunto de transformações na urbanização da região, tais como: a) a valorização dos centros localizados às margens das rodovias (geralmente ao longo das principais rodovias de integração, como a Belém- Brasília, a PA-150 e a Transamazônica); b) a reprodução de pequenos núcleos dispersos - povoados e vilas - vinculados à mobilidade do trabalho; c) a retração de núcleos antigos; e d) a implantação de franjas urbanas avançadas (PEREIRA, 2006). 
Portanto, é de fundamental importância compreender a Amazônia em sua diversidade e complexidade. Embora existam conflitos em outras regiões, a dinâmica nunca é a mesma, ainda que haja pontos em comum, como: o Estado e o capital privado que exercem influências sobre o espaço; a luta dos agentes sociais; e, por outro lado, os agentes sociais que criam mecanismos de resistência para garantir seus direitos.

\begin{abstract}
Chega-se à maioria das pequenas cidades pelo rio e delas é possível contemplar uma paisagem cujo limite é o reencontro das paralelas no horizonte em que o céu e as águas parecem se abraçar. A paisagem citadina é avistada de longe, aparecendo aos poucos, preguiçosamente aos olhos de quem se aproxima sem pressa de chegar. Assim vista, a maioria destas pequenas cidades situadas às margens dos rios assemelha-se a um quadro emoldurado pela folhagem verdeescuro da floresta que lhe guarnece. "Parece um recanto sedutor" (OLIVEIRA, 1999, p. 200).
\end{abstract}

O processo de produção do espaço amazônico ocorre graças à ação de vários sujeitos, tais como: pequenos agricultores, pescadores, populações ribeirinhas, assalariados, posseiros peões, caboclos e povos indígenas. De outro lado, os constituintes do capital privado são: as empresas, o capital financeiro e as multinacionais, além do Estado, que atua como agente que possibilita a produção da Amazônia como fronteira (OLIVEIRA, 1999).

Ainda segundo o autor, o modo como se produz o espaço depende das condições dos meios de produção e da forma como a vida se manifesta, por este motivo, o espaço não pode ser reduzido à natureza nem ao ambiente construído, pois compreende as formas de controle que se adequam à produção dos meios materiais para a existência do homem. Desse modo, conforme Oliveira:

O espaço urbano que se produz num lugar qualquer da Amazônia não é único. Ele está contido e contém uma totalidade que inclui tanto o processo de desenvolvimento recente para a região, como a forma de produção da sociedade nacional, refletindo a maneira da espacialização de outras cidades brasileiras assinalada pela contradição: de um lado, as ilhas de luxo, riqueza, bem-estar, e de outro, os arquipélagos de extrema miséria (OLIVEIRA, 1999, p. 203).

Assim, a análise do processo de produção do espaço na Amazônia pressupõe o entendimento de que este não se encerra em si mesmo, pois é condição, meio e produto da sociedade. O espaço existe fora do indivíduo, é produto, mas também se imbrica na produção da sociedade. Neste contexto, abrange não apenas as relações de produção, 
mas também abarca as dimensões política, cultural, dentre outras. Logo, sua produção possui dimensão de totalidade.

\begin{abstract}
Considerado apenas como aparente, o cotidiano pode ser o ponto de partida para a investigação da realidade, pois ela não está à margem da vida de cada dia. Mas o cotidiano não é só isso, é também o receptáculo da passividade, da desesperança, da repetitividade enfadonha, da falta de perspectiva, enfim, da miséria do dia a dia e, no caso, nos confins da Amazônia. E mais: é, sobretudo, o que contém a possibilidade de mudança da vida, pois ele também possui uma dimensão de riqueza não apenas material, concentrada nas mãos de poucos, mas virtual, que reproduz a vida e que aponta para o fato de que o social não se restringe ao econômico, indo além ao se referir às relações sociais entre os indivíduos, entre estes e o grupo e deste com a sociedade (OLIVEIRA, 1999, p. 203).
\end{abstract}

O fenômeno da urbanização polarizou a relação cidade-campo até os dias atuais, desse modo, tudo que se relaciona com a vida no campo significa "tradição", "atraso", em contraposição à noção de modernidade, que passou a ser associada à vida na cidade. Essa polarização permeia as relações sociais na Amazônia, na vida presente, pois a relação sociedade e natureza é impregnada de contradições sociais, o que leva à emergência de um campo de lutas e disputas pela apropriação do território (CRUZ, et al., 2012).

A dimensão urbana da região amazônica resulta dos nexos estabelecidos por aspectos relacionados: à exploração dos recursos naturais, à produção de territórios, às políticas públicas, ao crescimento populacional, ao desempenho e impacto dos grandes projetos de infraestrutura e econômicos, à ocupação e disputa pelo espaço de moradia e ao planejamento do desenvolvimento urbano e territorial (CRUZ, et al., 2012).

A produção do espaço urbano na Amazônia se dá a partir de um processo conflituoso, pelo qual as novas relações destroem e reconstroem as velhas, produzindo um espaço controlado e homogeneizado. Desse modo, o espaço urbano reproduz as diferenças e as resistências que recriam as antigas relações, mas não é capaz de restaurálas. É neste contexto que as populações locais criam condições de resistência, com o intuito de tentar alcançar as transformações do espaço produzido, e essas ações são verificadas na resistência da população indígena que briga para que o direito à diferença seja garantido. Para Castro, são:

Diferenças, rupturas e continuidades que se dão no tempo, buscando compreender as lógicas que estruturam as macro-regularidades no espaço e no 
tempo. E ainda traçar um caminho de interpretação sobre a cidade que procure dar conta das subjetividades, racionalidades e sentidos da ação (CASTRO, 2008, p. 14).

Oliveira (1999, p. 204) destaca que a expansão da fronteira da Amazônia se dá a partir de um processo contraditório, baseado no seguinte tripé: "destruição das formas espaciais existentes, a criação das resistências e a reconstrução das formas e conteúdos espaciais dotados de novas dimensões e significados." Portanto, a forma como esse espaço vem sendo produzido pode apresentar uma dualidade: por um lado, ser um instrumento de perda, por outro, uma alternativa para a libertação, que exige resistência de sujeitos que se contraponham ao que lhes vem sendo imposto nesses longos anos, contra a produção da vida vigente e contra o modo de opressão que vêm sofrendo.

Essas cidades se modificam a partir de sua inserção na estrutura produtiva e no mercado de trabalho, o que significa que antigos padrões de organização espacial estão sendo rompidos. Isto é resultado de investimentos econômicos e de ações do Governo que tiveram caráter pulverizado, abrindo as fronteiras econômicas para que o capital privado pudesse usufruir dos recursos naturais da região (OLIVEIRA, 1999).

Segundo Trindade Junior e Pereira (2007, p. 313), o "controle da terra, a política de migração induzida e financiada pelo Estado" associados aos incentivos fiscais asseguraram um espaço de valor para que o capital pudesse implantar suas estruturas, o que possibilitou também uma rápida ocupação da região, consolidando-a como fronteira agrícola.

A expansão da fronteira econômica no interior da região não se dá de maneira igual quando consideramos a especificidade das sub-regiões. A Amazônia Oriental, em particular, tende a acompanhar um processo que já vem sendo verificado há algum tempo no restante do território brasileiro (TRINDADE JUNIOR; PEREIRA, 2007, p. 315).

De acordo com Barbieri e Monte-Mór (2008), a urbanização da Amazônia brasileira manifesta-se por meio das múltiplas centralidades e extensões urbanas das cidades: das vilas para os centros comerciais e de serviços, instalações industriais, fazendas, comunidades locais, seringais e áreas indígenas, o que produz uma variedade de locais mais ou menos conectados ao capitalismo urbano-industrial. Essa urbanização, que é característica da região amazônica, carrega, em sua essência, o processo e as formas socioespaciais próprias do capitalismo industrial e suas múltiplas manifestações globais contemporâneas. 
Embora cerca de $70 \%$ da população amazônica viva em núcleos urbanos, a urbanização é negligenciada nos estudos sobre a região. As cidades têm papel fundamental no processo de ocupação e na tentativa de desenvolvimento, pois "os núcleos urbanos foram as pontas de lança para a ocupação do território, pequenos aglomerados com poder mais simbólico do que efetivo, mas que garantiram sua posse" (BECKER, 2013, p. 11).

Por conta das políticas implementadas pelo governo, inúmeras transformações aconteceram na região, principalmente, o crescimento de centros às margens das rodovias e a reprodução de pequenos núcleos, povoados e vilas vinculados às proximidades do trabalho, entre outras mudanças. Observa-se, de um lado, o crescimento das metrópoles de forma dispersa, e do outro lado, o crescimento de pequenas e médias cidades.

Conhecer a realidade urbana da Amazônia é de extrema importância para que se possa compreender os diversos processos contraditórios da modernização que chegam, se instalam e modificam a realidade da região.

Segundo Castro (2003), para se entender as cidades da Amazônia é necessário compreender a relação que estas têm com o mundo, de certa forma rural: o mundo das atividades da agricultura, o mundo da pesca, das atividades mais distantes do núcleo central ou da localização dos serviços urbanos. Torna-se necessário avançar em pesquisas que revelem as particularidades das pequenas cidades, especialmente, no que se refere às expressões da questão social, para que se possa identificar os indicadores sociais, econômicos e culturais dessa particularidade, para que estes sirvam de base ao planejamento e execução de políticas públicas para a região.

\section{Considerações finais}

Na Amazônia, grande parte da população vive em áreas urbanas, com destaque, nas pequenas e médias cidades. No entanto, as políticas governamentais pouco consideram a realidade desses territórios.

A realidade brasileira é bastante diversificada e há um desconhecimento do governo federal sobre a realidade das cidades, especialmente, das pequenas. $\mathrm{O}$ conhecimento das peculiaridades das pequenas cidades amazônicas é fundamental para 
que as diversidades regionais, municipais e urbanas sejam incorporadas na formulação de políticas públicas que respondam às expressões da questão social na região.

Quando se trata das pequenas cidades na Amazônia, o planejamento e a gestão do desenvolvimento urbano constituem um desafio árduo, uma vez que há pouco envolvimento político dos sujeitos locais na formulação e implementação de políticas e programas sociais, além da baixa influência desses municípios no âmbito das políticas nacionais, pois estes são pouco atrativos no que se refere à reprodução do capital.

O marco regulatório nacional elege diretrizes para o embasamento da política urbana, dando ênfase à questão fundiária e à gestão democrática. No entanto, essas diretrizes continuam reproduzindo os modos tradicionais de se olhar a cidade, ou seja, seu foco é a cidade de grande porte, conforme o padrão do eixo Sul-Sudeste, e, com base nesse critério, apontam os caminhos para o desenvolvimento das cidades de modo geral.

Nota-se, assim, que as análises sobre as pequenas cidades da Amazônia apontam, sinteticamente, mas não se esgotam aí, os seguintes elementos constitutivos da peculiaridade da dimensão urbana dessas pequenas cidades: a) baixa densidade populacional; b) precário acesso à infraestrutura física e social, devido à pouca atratividade aos empreendimentos capitalistas, considerando o lugar dessas cidades na divisão social e territorial do trabalho e a priorização do Estado em infraestrutura que redunde em lucros para essas empresas; b) existência de modo de vida diferenciado, pelos aspectos culturais indígenas, quilombolas e ribeirinhos que compõem a complexa rede urbana/rural; c) difícil acesso a algumas cidades, devido às distâncias geográficas entre as mesmas, inclusive, com acesso pelos rios; d) reprodução dos elementos universais da desigualdade econômica e social, expressos pela dificuldade de acesso ao trabalho, pelo baixo nível salarial dos habitantes e pelo frágil acesso às políticas públicas e sociais, agravados, enormemente, pela falta de conhecimento/priorização, por parte do governo federal, das particularidades regionais; e) baixa capacidade administrativa municipal, com frágil arrecadação e fraca proposição ao planejamento governamental; f) registro de resistência dos povos indígenas pelo direito à permanência em seu lugar, diante dos grandes empreendimentos capitalistas (a exemplo da construção da Hidrelétrica de Belo Monte), e das comunidades ribeirinhas e quilombolas, pelo modo de 
viver, o que imbrica elementos da vida urbana e rural, com atividades produtivas baseadas na pesca, extrativismo, agricultura, dentre outros.

Dessa forma, o conhecimento das peculiaridades econômicas, sociais e culturais é fundamental para que o planejamento e a intervenção governamental incorporem as realidades municipais, notadamente, as particularidades históricas de cada município, como forma de garantir os direitos econômicos, sociais e culturais dos habitantes das pequenas cidades da Amazônia.

\section{Referências}

BARBIERI, A.; MONTE-MÓR, R. L. M. Mobilidade populacional e urbanização na Amazônia: elementos teóricos para uma discussão. In: RIVERO, Sérgio. As Amazônias do século XXI. Belém: UFPA, 2008. v. 1, p. 89-103.

BECKER, B. K. A urbe Amazônida: a floresta e a cidade. Rio de Janeiro: Garamond, 2013. CARDOSO, A. C. D. O rural e o urbano na Amazônia: diferentes olhares em perspectivas. Belém: EDUFPA, 2006.

CARDOSO, I. C. C. Cidade capitalista e política urbana no Brasil do século XXI: como pensar a realidade periurbana? In: SANTANA, J.; HOLANDA, A. C. G.; MOURA, A. S. F. A questão da habitação em municípios periurbanos na Amazônia. Belém: UFPA, 2012. p. 29-52.

CARVALHO, G. O desafio urbano amazônico. In: SANTANA, J.; HOLANDA, A. C. G.; MOURA, A. S. F. A questão da habitação em municípios periurbanos na Amazônia. Belém: UFPA, 2012.

CASTELLS, M. A questão urbana. Rio de Janeiro: Paz e Terra, 1983. (Coleção Pensamento Crítico, v. 48).

CASTRO, E. Relações campo-cidade, identidades e redes de sociabilidade na Amazônia. Relação campo-cidade e Identidades Regionais nas Amazônias In: WORKSHOP SUSAM, 2.2003, Belém. Anais.... Belém, 2003.

CASTRO, E. Urbanização, pluralidade e singularidades das cidades amazônicas. In:

CASTRO, E. Cidades na floresta. São Paulo: Annablume, 2008. p. 13-39.

CORRÊA, R. L. A rede urbana. São Paulo: Ática, 1989.

CORRÊA, R. L. O espaço urbano. 4. ed. São Paulo: Ática, 2004.

CORRÊA, R. L. Uma nota sobre o urbano e a escala. Revista Território, Rio de Janeiro, n. 11, set./out. 2003.

CRUZ, S. H. R. et al. Processo de urbanização, moradia e plano municipal de habitação no município de Xinguara-Pa. In: SANTANA, J.; HOLANDA, A. C. G.; MOURA, A. S. F. A questão da habitação em municípios periurbanos na Amazônia. Belém: UFPA, 2012. 
ENDLICH, A. M. Pensando os papéis e significados das pequenas cidades no Noroeste do Paraná. 2006. 505p. Tese (Doutorado em Geografia) - Universidade Estadual Paulista, Presidente Prudente, 2006.

JURADO, P. F. S. Cidades pequenas e indústria: contribuição para a análise da dinâmica econômica na região de Presidente Prudente. 2011. 282 f. Dissertação (Mestrado em Geografia) - Universidade Estadual Paulista, Presidente Prudente, 2011.

LAKATOS, E. M.; MARCONI, M. A. Metodologia científica. 5. ed. São Paulo: Atlas, 2011.

LEAL, Al. Uma sinopse histórica da Amazônia. Revista de estudos paraenses. Edição Especial, Belém, 2010.

LEFEBVRE, H. A cidade do capital. Rio de Janeiro: DP\&A, 1969.

LOPES, D. M. F. Cidades pequenas do semiárido: dinâmicas sociodemográficas e marginalização. 2010. Disponível em: <http://www.abep.nepo.unicamp.br/ encontro2010/docs_pdf/eixo_1/abep2010_2378.pdf>. Acesso em: 14 jun. 2016.

MAIA, D. S. Cidades médias e pequenas do Nordeste: conferência de abertura. 2010. In: LOPES, D. M. F. Cidades médias e pequenas: teorias, conceitos e estudos de caso. Salvador: SEI, 2010. p. 13-37.

MARX, K. Introdução à crítica da economia política. In: . Manuscritos econômicosfilosóficos e outros textos escolhidos. São Paulo: Abril Cultural, 1974. (Coleção os Pensadores).

NAKANO, A. K. Desenvolvimento urbano e territorial em municípios periurbanos: diferenciações no universo dos municípios brasileiros. In: SANTANA, J.; HOLANDA, A. C. G.; MOURA, A. S. F. A questão da habitação em municípios periurbanos na Amazônia. Belém: UFPA, 2012.

NAKANO, A. K. Desenvolvimento urbano e territorial em municípios perirubanos, diferenciações no universo dos municípios brasileiros. In: FASE - FEDERAÇÃO DE ÓRGÃOS PARA ASSISTÊNCIA SOCIAL E EDUCACIONAL. Municípios periurbanos e direito à cidade: uma agenda em construção. Belém: FASE; Observatório Comova, 2011.

NASCIMENTO, N. S. F.; SÁ, M. E. R. Acumulação de capital e cidades na Amazônia: produção de riquezas e negação de direitos sociais. In: GOMES, V. L. B. et al. $O$ avesso dos direitos: Amazônia e Nordeste em questão. Recife: UFPE, 2012.

OLIVEIRA, J. A. As pequenas cidades da Amazônia: espaços perdidos e reencontrados. São Paulo: Contexto, 1999.

PEREIRA, J. C. M. A urbanização da Amazônia e o papel das cidades médias na rede urbana regional. In: CARDOSO, A. C. D. C. O rural e o urbano na Amazônia: diferentes olhares em perspectivas. Belém: UFPA, 2006.

PICOLI, F. O capital e a devastação da Amazônia. São Paulo: Expressão Popular, 2006.

RIBEIRO, R. A política habitacional recente e sua expressão em municípios da Amazônia Oriental: os exemplos de São Sebastião da Boa Vista e São João do Araguaia/PA. In: 
SANTANA, J.; HOLANDA, A. C. G.; MOURA, A. S. F. A questão da habitação em municípios periurbanos na Amazônia. Belém: UFPA, 2012.

RODRIGUES, E. B. Aventura urbana: urbanização, trabalho e meio ambiente em Belém. Belém: NAEA, 1996.

SANTANA, J. V. Pequenas cidades na Amazônia: desigualdade e seletividade no investimento da infraestrutura habitacional. In: SANTANA, J.; HOLANDA, A. C. G.; MOURA, A. S. F. A questão da habitação em municípios periurbanos na Amazônia. Belém: UFPA, 2012.

SANTANA, J. V.; HOLANDA, A. C. G. Desafios da implementação da política habitacional em pequenos municípios paraenses: a questão da habitação e da fragilidade administrativa. In: GOMES, V. L. B. et al. $O$ avesso dos direitos: Amazônia e Nordeste em questão. Recife: UFPE, 2012.

SANTANA, J.; HOLANDA, A. C.G.; MOURA, A. S. F. A questão da habitação em municípios periurbanos na Amazônia. Belém: UFPA, 2012.

SANTOS, M. Espaço e sociedade. Petrópolis: Vozes, 1982.

SANTOS, M. Técnica, espaço e tempo: globalização e meio técnico-científicoinformacional. São Paulo: Hucitec, 1994.

SCHOR, T. et al. Cidades, rede urbana e desenvolvimento na Amazônia dos grandes rios. In: TRINDADE JUNIOR, S. C. et al. Pequenas e médias cidades na Amazônia. Belém: FASE; Observatório Comova, 2009.

SPOSITO, M. E. B. Para pensar as pequenas e médias cidades brasileiras. Belém: FASE, 2009.

TRINDADE JUNIOR, S. C. C; TAVARES, M. G. C. Cidades ribeirinhas na Amazônia: mudanças e permanências. Belém: NAEA, 2008.

TRINDADE JUNIOR, S. C. et. al. Pequenas e médias cidades na Amazônia. Belém: FASE, 2009.

TRINDADE JUNIOR, S. C.; PEREIRA, J. C. M. Reestruturação da rede urbana e importância das cidades médias na Amazônia Oriental. In: SPOSITO, M. E. B. (Org.) Cidades médias: espaços em transição. São Paulo: Expressão Popular, 2007.

VICENTINI, Y. Cidade e história na Amazônia. 1994. Tese (Doutorado em Planejamento Urbano) - Universidade de São Paulo, São Paulo, 1994. 